\title{
Linear systems over Hermite rings. Some pole-placement results
}

Miguel Carriegos ${ }^{1}$ and M. Teresa Trobajo ${ }^{1}$

${ }^{1}$ Universidad de León

September 11, 2020

\begin{abstract}
A Kalman reduced form is obtained for linear systems over Hermite rings. This reduced form gives information of the set of assignable polynomials to a given linear system.
\end{abstract}

\section{Hosted file}

Carriegos_Trobajo_Linear_Problems_Over_Bezout_Rings.pdf available at https://authorea.com/ users/358264/articles/480465-linear-systems-over-hermite-rings-some-pole-placementresults 